\title{
INCENTIVOS E SUBSÍDIOS PARA IMPORTAÇÃO DE ACESSÓRIOS, EQUIPAMENTOS E MEDICAMENTOS PARA PORTADORES DE NECESSIDADES ESPECIAIS (PNE)
}

\section{ARTIGO ORIGINAL}

QUADROS, Eduardo Nunes ${ }^{1}$

QUADROS, Eduardo Nunes. Incentivos e subsídios para importação de acessórios, equipamentos e medicamentos para Portadores de Necessidades Especiais (PNE). Revista Científica Multidisciplinar Núcleo do Conhecimento. Ano 05, Ed. 03, Vol. 03, pp. 184-205. Março de 2020. ISSN: 2448-0959, Link de acesso: https://www.nucleodoconhecimento.com.br/lei/incentivos-e-subsidios

\section{RESUMO}

O número de Portadores de Necessidades Especiais no Brasil é grande e a necessidade de acessibilidade mostra a importância de propiciar, aos mesmos, condições de aquisição de acessórios, equipamentos e medicamentos específicos. Entretanto, no Brasil, esses produtos ainda têm um alto preço e os que podem dispor de dinheiro gostariam de importar esses produtos, entretanto, o imposto de importação é alto, o que inviabiliza o processo. Nesse sentido, alguns projetos de lei foram impetrados buscando conceder isenção de imposto de importação aos Portadores de Necessidades Especiais. Trata-se de um assunto relevante e que possui, ainda, escasso material, especificamente sobre a questão dos incentivos e subsídios aos Portadores de Necessidades Especiais (PNE) no que diz respeito à importação de acessórios, equipamentos e medicamentos. Diante disso, objetiva-se, com esse artigo, verificar, a partir de levantamentos e estudos de leis e de projetos de leis, se os incentivos e subsídios a que os Portadores de Necessidades Especiais têm

\footnotetext{
${ }^{1}$ Mestre em Direito e Negócios Internacionais pela Universidad Europea del Atlántico; Engenheiro Civil pela Fundação Mineira de Educação e Cultura - FUMEC-BH; Bachareu em Direito pela Faculdade Unievangélica - Anápolis.
} 
direito para importação de acessórios, equipamentos e medicamentos têm sido aplicados de maneira correta e ampla. A metodologia é descritiva e contou com um levantamento bibliográfico e explanação de dados do IBGE (2010) e da Pesquisa Nacional de Saúde (2018). Diante dos dados apresentados, concluiu-se que os incentivos e subsídios a que os Portadores de Necessidades Especiais têm direito para importação de acessórios, equipamentos e medicamentos ainda não têm sido aplicados de maneira correta e ampla, isso porque os projetos de lei estão parados e alguns já foram arquivados e a causa disso diz respeito a questões orçamentárias. Além disso, a pesquisa trouxe dados suficientes que comprovam a importância da isenção de impostos para importação de acessórios, equipamentos e medicamentos para Portadores de Necessidades Especiais (PNE).

Palavras-chave: Portadores de Necessidades Especiais, Direito. Tributos, importação, isenções.

\section{INTRODUÇÃO}

A UNESCO elaborou, em 1950, o Acordo de Florença e nele está prevista a livre circulação e importação de produtos de cunho educativo, científico ou cultural, estando isento do pagamento de tarifas de importação de qualquer tipo os produtos para pessoas com necessidades especiais. Entretanto, isso somente será possível se o produto em questão não for produzido no Brasil, o que fundamenta a necessidade da importação (MAIO, 1999). De maneira inexplicável, o Brasil, que tem quase $24 \%$ da população brasileira com algum tipo de deficiência (45 milhões de pessoas), não faz parte do acordo (IBGE, 2018). Nesse sentido, vários projetos de lei têm sido propostos e alguns têm sido aprovados, mas é necessário um maior entendimento sobre o assunto devido à sua complexidade e relevância. Diante disso, o problema da pesquisa é: dentre as isenções de tributos que os Portadores de Necessidades Especiais têm direito, os ligados à importação de acessórios, equipamentos e medicamentos têm sido aplicados de maneira eficiente?

Trata-se de um assunto relevante e que possui, ainda, escasso material que aborda, especificamente, a questão dos incentivos e subsídios aos Portadores de 
Necessidades Especiais (PNE), sobretudo no que diz respeito à importação de acessórios, equipamentos e medicamentos. Sua relevância consiste no fato de que a abordagem dessa temática contribuirá para um melhor entendimento sobre os direitos dos Portadores de Necessidades Especiais (PNE), esclarecendo quais as ferramentas jurídicas existentes propiciam que estes possam importar insumos que trazem conforto e inclusão com a isenção de impostos. O objetivo geral desse artigo é verificar, a partir de levantamentos e estudos de leis e de projetos de leis, se os incentivos e subsídios a que os Portadores de Necessidades Especiais têm direito para importação de acessórios, equipamentos e medicamentos têm sido aplicados de maneira correta e ampla.

Como objetivos específicos espera-se: descrever os elementos conceituais e o panorama dos Portadores de Necessidades Especiais no Brasil e no Mundo; abordar os Direitos das Pessoas com Necessidades Especiais, enfatizando o seu papel no Plano Internacional e os Documentos Internacionais de Proteção a essas pessoas; abordar a acessibilidade como Direito Fundamental das Pessoas com Necessidades Especiais, descrevendo as várias dimensões existentes de acessibilidade; descrever a tributação e os Portadores de Necessidades Especiais, destacando a sua capacidade contributiva e as isenções de tributos a que têm direito, dentre os quais, os ligados à importação de acessórios, equipamentos e medicamentos e analisar os projetos de lei ligados às isenções de importação bem como as Leis já aprovadas e verificar os desafios ainda a serem enfrentados nesse sentido.

Considerando esse contexto, a perspectiva é trazer dados que capazes de demonstrar a importância e, também, a necessidade da isenção de impostos para importação de acessórios, equipamentos e medicamentos para Portadores de Necessidades Especiais (PNE), visto que nem todos conseguem ter acesso a eles devido as taxas elevadas. Espera-se, ainda, apresentar ferramentas jurídicas importantes para esclarecer e ajudar pessoas portadoras de necessidades especiais que têm condições de importar insumos que trariam conforto e inclusão, mas se deparam com profissionais da área de importação despreparados por não contarem com um estudo mais detalhado das legislações que cuidam desse assunto em todo o mundo. 


\section{OS DIREITOS DAS PESSOAS COM NECESSIDADES ESPECIAIS (PNE)}

A Constituição Federal de 1988 aborda os temas ligados a pessoas que apresentem algum tipo de deficiência. Eles se encontram dispostos em várias passagens. Em seu art. $7^{\circ} \S \mathrm{XXXI}$, proíbe a distinção no que diz respeito a estabelecimento de critérios específicos de admissão, dentre os quais níveis salariais diferenciados para o trabalhador "portador de deficiência". Por meio do art. $37 \S$ VIII, determina que a lei deve reservar um percentual específico dos cargos e empregos públicos para as pessoas que apresentam algum grau de "deficiência", estabelecendo, preliminarmente, os critérios de sua admissão. Dispõe, ainda, por meio do art. $203 \S$ II, que a Assistência Social deve habilitar e, também, reabilitar todas as pessoas "portadoras de deficiência" e promover sua integração à vida comunitária (BRASIL, 1988).

Estabelece, também, por meio do art. 227 § II, que o Estado tem o dever de elaborar programas de globalização comunitária do adolescente emissário de déficit a partir de treinamento para o trabalho e a coexistência e deve haver a facilitação da afluência aos bens e serviços coletivos para combater a extinção de preconceitos e obstáculos de acessibilidade. Além disso, o seu art. 244 se remete as disposições acerca da transposição das ruas, dos prédios de utilização pública e dos veículos de transporte coletivo, propiciando uma maior acessibilidade às pessoas com algum tipo de deficiência (BRASIL, 1988). Nesse sentido, a intenção dos constituintes foi dar efetividade a esses direitos e não os transformar em letra morta. A leitura dos diversos incisos do art. 5o deixa clara a existência de normas definidoras dos direitos das pessoas com algum tipo de necessidade especial (Ferreira Filho, 2010).

Buscando contornar as barreiras trazidas pelo veto ao art. 1ํ, IV, da Lei n. 7.347/85 e antecipando-se à Lei n. 8.078, de 11/09/90, a Lei n. 7.853/89 ratificou a atuação civil pública como solução processual para se apropriar da proteção dos interesses coletivos ou difusos dos indivíduos com alguma necessidade especial, pelo Ministério Público e pelos indivíduos jurídicos de Direitos Públicos assim como, também, por 
fundações, empresas públicas, associações, além de sociedades de economia mista (com a premissa que sejam incluídas, entre seus objetivos institucionais, a proteção de pessoas com necessidades especíais) (Abreu, 2009). Considerando a Lei n. 7.853/89, a partir de 1989, sob o prisma do Direito do Trabalho, foi realizada uma propositura de uma ação pública (ou coletiva) com o objetivo de defender os trabalhadores portadores de necessidades especiais, tornando obrigatória a construção de rampas que propiciam uma maior acessibilidade de paraplégicos ao local de trabalho (Lorentz, 2006).

Deve-se destacar, também, ainda no âmbito do Direito do Trabalho, o art. 8 II, visto que ele ficou responsável por tipificar como crime o ato de negar qualquer tipo de cargo público a pessoas que detém alguma necessidade especial, exclusivamente por terem essa condição. Essas pessoas poderão ser punidas com detenção de quatro anos, além do pagamento de multa (Lorentz, 2006). O Código Civil de 2002 assegurou um tratamento mais apropriado às pessoas com necessidades especiais. Entretanto, com relação as nomenclaturas utilizadas na designação daqueles que possuem deficiência, os termos utilizados como "deficiência mental", "enfermidade" e "excepcional sem desenvolvimento mental completo", continuam, ainda, sendo insuficientes para explicar o número elevado de casos, nesse sentido.

Neste âmbito, ainda existem pontos ligados a classificação e, mais especificamente, nomenclaturas que merecem uma maior apreciação por parte do legislador (Abreu, 2009). O legislador objetivou, ao colocar a nomenclatura "pessoa portadora de deficiência", desvincular a palavra deficiência para a pessoa, no entanto, esse intuito não foi efetivado, visto que o foco acabou recaindo mesmo é no termo portador, sugerindo que se trata de alguma patologia. Nesse caso, o termo mais usado passou a ser "pessoas com necessidades especiais" (Fávero, 2004). No que tange à comparação do grupo dos relativamente incapazes, no Código Civil de 2002 foram inseridos os que, "por deficiência mental, tenham o discernimento reduzido"[2] assim como "os excepcionais, sem desenvolvimento mental completo"[3].

Esta mudança representou um progresso considerável com relação à redação anterior, visto que foram indicados graus de incapacidade e, dessa forma, propiciou- 
se, ao indivíduo, a possibilidade de atingir a capacidade relativa, fato que antes não era possível (Requião, 2016). Desse modo, reconhece-se a importância da concessão da autonomia do indivíduo como um avanço no que diz respeito à manutenção da autonomia das pessoas com necessidades especiais, permitindo, a elas, o alcance da capacidade relativa (Schreiber, 2018). Em julho de 2015 foi publicada a Lei Brasileira de Inclusão da Pessoa com Deficiência (Lei no 13.146/15), também denominada de "Estatuto da Pessoa com Deficiência". É inegavelmente um instrumento à proteção dos direitos humanos, e

Vem atender uma população de quase 46 milhões de pessoas no Brasil, o que corresponde a $25 \%$ da população brasileira, que integram os $15 \%$ da população mundial, cerca de um bilhão de pessoas afetadas por algum tipo de deficiência (Schreiber, 2018, p.111).

Com esse Estatuto, foram alterados os dispositivos do Código Civil que abordavam a capacidade civil. Os artigos 114 e 123, inciso II, do referido documento, mudaram o caput e os incisos do artigo $3^{\circ}$ do CC que tratam da incapacidade absoluta foram revogados. Foram também modificados os incisos II e III do artigo 4 do CC, ligados aos relativamente incapazes (Brasil, 2017). Conforme o art. 3․ do Código Civil, somente os indivíduos menores de 16 anos são consideradas absolutamente incapazes e relativamente incapazes as pessoas entre 16 e 18 anos (art. 4ํ․ I, CC) (Schreiber, 2018). Anteriormente à introdução do supramencionado Estatuto ao ordenamento jurídico brasileiro, a regra era pela incapacidade da pessoa com deficiência. Entretanto, perante as mudanças trazidas por ele, as pessoas com deficiência foram excluídas do conjunto das incapacidades (Schreiber, 2018).

Neste sentido, de acordo com Oliveira (2016), ao não considerar os portadores de deficiência mental ou intelectual como totalmente incapazes, considera-se os mesmos incapazes de forma relativa, o que se mostra um grande equívoco (artigo 4ํㅡㄴ, III, do $\mathrm{CC})$. As alterações oriundas do Estatuto consolidam e atendem os critérios adotados pela Convenção sobre os Direitos das Pessoas com Deficiência. Tal documento representa um grande avanço para a proteção da dignidade da pessoa com deficiência. Essas inovações são oriundas de um processo intenso que teve como 
objetivo incluir socialmente as pessoas com necessidades especiais bem como a garantia do seu direito à cidadania efetiva e plena (Vorcaro; Gonçalves, 2018).

\section{A ACESSIBILIDADE COMO DIREITO FUNDAMENTAL DAS PESSOAS COM NECESSIDADES ESPECIAIS (PNE)}

A acessibilidade é, sem dúvida, um dos instrumentos primordiais que asseguram a inclusão social, uma vez que busca garantir o acesso das pessoas de forma imparcial aos outros direitos, mesmo que se enquadrem como direitos fundamentais (NISHIYAMA; TEIXEIRA; SILVA, 2016). Trata-se de um ato que está ligado à dignidade da pessoa humana, visto que propicia liberdade quanto ao acesso à justiça, possibilitando o exercício pleno dos seus direitos (Sassaki, 2008). A primeira previsão expressa no ordenamento jurídico do termo acessibilidade ocorreu por meio da Emenda Constituição no 12, promulgada em 1967. O texto da referida emenda busca garantir, às pessoas com necessidades especiais, uma melhor qualidade de vida tanto econômica quanto social, especialmente no que tange à acessibilidade nas ruas e edifícios.

Embora ainda seja limitada, tal emenda representa um avanço no que diz respeito à proteção dessa camada da população tendo servido de base para a interposição de medidas judiciais para que fossem implantadas rampas que facilitam o acesso tanto em locais privados como públicos (Araújo, 2001). Entretanto, este direito só ganhou a devida relevância no ano de 2006, quando ocorreu a Convenção sobre os Direitos das Pessoas com Deficiência em Nova lorque. Preliminarmente, foi verificada a relevância de uma maior acessibilidade aos locais da mesma forma que é importante o acesso à saúde e educação (NISHIYAMA; TEIXEIRA; SILVA, 2016). A Convenção sobre os Direitos das Pessoas com Deficiência teve como norte principal a acessibilidade. Isso ficou claro pelo fato que há um artigo inteiro (artigo 9º) que aborda os aspectos ligados a essa questão (Barcellos; Campante, 2012).

O conceito de acessibilidade possui uma amplitude muito grande, englobando todas as esferas de interação social e não somente as barreiras de interação social. Neste contexto, é possível definir acessibilidade como sendo: "o mecanismo por meio do 
qual se vão eliminar as desvantagens sociais enfrentadas pelas pessoas com deficiência, pois dela depende a realização dos seus demais direitos" (Barcellos; Campante, 2012, p. 177). Lopes (2009) afirma que o "estado de acesso" proposto pela Convenção Internacional estabelece que todas as barreiras existentes que impossibilitam o livre acesso das pessoas com necessidades especiais devem ser extintas e que todas as readaptações necessárias devem ser feitas, buscando facilitar o pleno direito ao acesso a todos os locais.

O Estado tem papel primordial na garantia do acesso dessas pessoas, seja em locais privados ou públicos, visto que é sua obrigação a implantação e a fiscalização da aplicação da norma. $O$ direito à acessibilidade está estabelecido na Constituição Federal e em várias normas infraconstitucionais, entretanto, nesse momento, é importante ressaltar que o princípio da acessibilidade não está limitado à acessibilidade arquitetônica. Para tanto, é imprescindível um maior planejamento político para a inclusão da pessoa com deficiência (Ohlweiler, 2014). O acesso aos direitos que devem ser assegurados pelo Estado é feito a partir de políticas públicas, uma vez que se trata de um "conjunto de ações elaboradas pelo poder público para efetivar as indicações de bem comum, justiça social e a igualdade dos cidadãos" (Ohlweiler, 2014, p. 133).

Cabe salientar que a acessibilidade nada mais é do que um direito primordial das pessoas com necessidades especiais. Nesse sentido, o acesso a acessórios, equipamentos e medicamentes que propiciam uma maior qualidade de vida é um direito, sendo que isentá-las dos tributos cobrados pela importação desses produtos é primordial para a maximização da sua acessibilidade (Barcellos; Campante, 2012). Buscando a garantia da dignidade da pessoa com deficiência é necessário que sejam respeitadas as condições para que sejam exercidos de forma plena os seus direitos fundamentais (Silveira, 2010). A pessoa com deficiência tem sua dignidade humana assegurada quando os seus direitos à individualidade e à integridade física e moral não são tirados (NISHIYAMA; TEIXEIRA; SILVA, 2016).

Uma maior preocupação sobre a necessidade de uma maior inclusão das pessoas com necessidades especiais ocorreu na década de 70 e isso aconteceu porque vários 
segmentos organizados passaram a se mobilizar e promover campanhas em nível mundial, objetivando destacar a necessidade de ações para a remoção de barreiras de acessibilidade no âmbito arquitetônico que dificultam à locomoção e o acesso dessas pessoas à vida em sociedade (NISHIYAMA; TEIXEIRA; SILVA, 2016). Embora essa preocupação tenha ocorrido nessa época, ainda são incipientes o número de rampas, tanto nas calçadas como nos edifícios, para cadeirantes além da falta de pisos podotáveis e sonorização nos elevadores. A implementação dos mecanismos de acesso começaram a ser considerada a partir da década de 90 (Ohlweiler, 2014).

\section{A TRIBUTAÇÃO E AS PESSOAS COM NECESSIDADES ESPECIAIS (PNE)}

Os benefícios fiscais são baseados nos princípios constitucionais, tais como: o princípio da igualdade, da legalidade e da capacidade contributiva. No caso específico do princípio da capacidade contributiva, somente poderá ser concedido o benefício às pessoas que não possuam capacidade econômica para arcar com o ônus do tributo. Nesse caso, essas pessoas são beneficiadas em certos tributos, por meio de reduções e até isenções de algumas alíquotas (Torres, 2010).

As pessoas com necessidade especiais, devido às suas condições, acabam, ao logo da vida, tendo gastos maiores com a saúde e com a busca por qualidade de vida. Nesse sentido, os gastos são oriundos da aquisição de aparelhos que promovem uma acessibilidade maior, remédios e produtos de uso exclusivo e que, normalmente, por serem exclusivos, tem um valor alto (Sabbag, 2006).

Visando minimizar os impactos financeiros dessas pessoas trazidos pelos custos excessivos gastos, o Poder Legislativo tem, cada vez mais, concedido a isenção do pagamento de impostos tributários, possibilitando, assim, uma qualidade de vida maior as pessoas com algum tipo de deficiência ou acometido com alguma doença grave. Dessa forma, propicia um bem-estar maior àqueles que necessitam superar as adversidades diárias, efetivando o princípio basilar da dignidade da pessoa humana (Cantarelli, 2015). 
No âmbito tributário, a dignidade humana não tem recaído diretamente na resolução dos casos, embora tenha sido entendida por meio de jurisprudência do Supremo Tribunal Federal, sobretudo no que se trata da proibição da utilização de tributos ligados ao confisco ou que dificultam a dignidade do contribuinte (Torres, 2010). Diversos são os benefícios fiscais que os portadores de necessidades especiais tem direito, entretanto, muitos ainda não tem conhecimento de todas as concessões a que podem usufruir.

\section{A ISENÇÃO DO IMPOSTO SOBRE A CIRCULAÇÃO DE MERCADORIAS E SERVIÇOS NA COMPRA DE VEÍCULOS PARA PESSOAS PORTADORAS DE NECESSIDADES ESPECIAIS (ICMS)}

A concessão da isenção do ICMS as pessoas com algum tipo de deficiência está estabelecida tanto no art. 19 do Anexo I do Regulamento do ICMS/2000 como nos convênios 35/99 e 03/2007 do Conselho Nacional de Política Fazendária (CONFAZ). Os pontos principais de cada norma são:

Anexo I do Regulamento do ICMS/2000: Artigo 19 - (DEFICIENTE FìSICO - VEİCULO AUTOMOTOR) - Saída interna ou interestadual de veículo com características específicas para ser dirigido por motorista portador de deficiência física, desde que a respectiva isenção seja amparada por isenção sobre o Imposto sobre Produtos Industrializados - IPI, nos termos da legislação federal vigente[4].

No que diz respeito ao convênio 35/99, observa-se que:

Cláusula primeira. Ficam isentas do ICMS as saídas internas e interestaduais de veículo automotor novo com até $127 \mathrm{HP}$ de potência bruta (SAE) que se destinar a uso exclusivo do adquirente, paraplégico ou portador de deficiência física, impossibilitado de utilizar o modelo comum, nos termos estabelecidos na legislação estadual. 
Por meio de tal lei é possível verificar, e, também, comprovar, que a concessão de isenção do ICMS para compra de veículo é um benefício voltado exclusivamente para pessoas com deficiência física, desde que esta não tenha condições de dirigir um veículo de modelo comum. Além disso, o veículo precisa de utilização exclusiva do adquirente, não sendo permitida, de nenhuma forma, que uma terceira pessoa venha a dirigi-lo, mesmo que em benefício do deficiente. Essa concessão é dada somente para deficiências físicas (Cantarelli, 2015).

No Regulamento do ICMS há uma referência no que diz respeito à isenção do veículo do IPI. Dessa forma, é preciso analisar a lei que aborda sobre a isenção do Imposto sobre Produtos Industrializados - IPI. Preliminarmente, esse benefício fiscal era destinado unicamente aos portadores de deficiência física que estivessem impossibilitados de dirigir um modelo comum. Posteriormente, houve uma alteração na redação que deixa claro que outras deficiências são contempladas nessa isenção tributária. Anteriormente à promulgação da Lei Federal n. 8.989 de 24 de fevereiro de 1995 a redação era:

Art. $1^{\text {o }}$ Ficam isentos do Imposto sobre Produtos Industrializados (IPI) os automóveis de passageiros de fabricação nacional de até 127 HP de potência bruta (SAE), de no mínimo quatro portas, inclusive a de acesso ao bagageiro, movidos a combustíveis de origem renovável, quando adquiridos por:[5]

IV - pessoas que, em razão de serem portadoras de deficiência física, não possam dirigir automóveis comuns.

Art. 10 Ficam isentos do Imposto Sobre Produtos Industrializados - IPI os automóveis de passageiros de fabricação nacional, equipados com motor de cilindrada não superior a dois mil centímetros cúbicos, de no mínimo quatro portas inclusive a de acesso ao bagageiro, movidos à combustíveis de origem renovável ou sistema reversível de combustão, quando adquiridos por[6]: 
IV - pessoas portadoras de deficiência física, visual, mental severa ou profunda, ou autistas, diretamente ou por intermédio de seu representante legal[7];

§ 10 Para a concessão do benefício previsto no art. 10 é considerada também pessoa portadora de deficiência física aquela que apresenta alteração completa ou parcial de um ou mais segmentos do corpo humano, acarretando o comprometimento da função física, apresentando-se sob a forma de paraplegia, paraparesia, monoplegia, monoparesia, tetraplegia, tetraparesia, triplegia, triparesia, hemiplegia, hemiparesia, amputação ou ausência de membro, paralisia cerebral, membros com deformidade congênita ou adquirida, exceto as deformidades estéticas e as que não produzam dificuldades para o desempenho de funções[8].

§ 20 Para a concessão do benefício previsto no art. 10 é considerada pessoa portadora de deficiência visual aquela que apresenta acuidade visual igual ou menor que 20/200 (tabela de Snellen) no melhor olho, após a melhor correção, ou campo visual inferior a $20^{\circ}$, ou ocorrência simultânea de ambas as situações[9].

§ $30 \mathrm{Na}$ hipótese do inciso IV, os automóveis de passageiros a que se refere o caput serão adquiridos diretamente pelas pessoas que tenham plena capacidade jurídica e, no caso dos interditos, pelos curadores[10].

§ 40 A Secretaria Especial dos Diretos Humanos da Presidência da República, nos termos da legislação em vigor e o Ministério da Saúde definirão em ato conjunto os conceitos de pessoas portadoras de deficiência mental severa ou profunda, ou autistas, e estabelecerão as normas e requisitos para emissão dos laudos de avaliação delas[11].

$\S 50$ Os curadores respondem solidariamente quanto ao imposto que deixar de ser pago, em razão da isenção de que trata este artigo[12]. 
$\S 60$ A exigência para aquisição de automóveis equipados com motor de cilindrada não superior a dois mil centímetros cúbicos, de no mínimo quatro portas, inclusive a de acesso ao bagageiro, movidos a combustíveis de origem renovável ou sistema reversível de combustão não se aplica aos portadores de deficiência de que trata o inciso IV do caput deste artigo[13].

Por meio de uma verificação do conteúdo exposto na legislação do ICMS e do IPI, observa-se que antes de 2003 havia uma equiparação dos beneficiários da isenção, mas com o tempo alterações se mostraram necessárias (Torres, 2010). Essas alterações ocorreram após junho de 2003, prioritariamente no que tange à isenção de IPI que passou a ser concedida para pessoas portadoras de diversos tipos de deficiência, incluindo a física, visual, mental com grau severo e até autistas, mas sempre tendo como norte a Legislação Federal que definiu a pessoa com deficiência. Essa alteração não ocorreu com a legislação do ICMS, visto que continua a isentar do tributo unicamente o deficiente físico (Torres, 2010). Essa situação tem se revelado discriminatória, uma vez que é incoerente estabelecer restrições da concessão do benefício levando em consideração o tipo de deficiência.

É insuficiente o argumento de que a isenção tem por objeto compensar as despesas a serem suportadas em razão da adaptação do veículo, uma vez que há certas adaptações, como, por exemplo, a colocação de direção hidráulica e câmbio automático e estas, na verdade, já estão inclusas em determinados modelos de automóveis (Cantarelli, 2015). Bolonhini Júnior (2004), ao analisar, no Estado de São Paulo, a concessão de isenção do ICMS para compra de veículos automotores, verificou que não há necessidade de adaptação nos automóveis de portadores de deficiência física que não podem dirigir e nem dos portadores de deficiência visual que não estão sendo beneficiados da isenção tributária do ICMS nas operações que envolvam veículos automotores.

Trata-se de uma situação incoerente e lamentável e a não isenção tem tornado o tratamento fiscal além de discrepante, também repleto de discriminação. A cobrança do ICMS é de competência do Estado que, também, tem a função de fiscalizar, 
sabendo-se que os fatos geradores, a base de cálculo e a definição dos contribuintes são estipulados pelas leis de cada estado, tendo como base as Leis Complementares no 87 de 1996 e o 53 de 1986 (Torres, 2010). Cabe mencionar que os convênios e regulamentos relativos à isenção do ICMS somente poderão ser conseguidos por pessoas que apresentem deficiência física, mas que são capazes de dirigir um veículo automotor adaptado (Cantarelli, 2015).

\section{METODOLOGIA}

A pesquisa contará com um levantamento bibliográfico que dará forma ao embasamento teórico, e, assim, conta com uma descrição dos impostos a que os portadores de necessidades especiais já tem direito bem como com a análise dos projetos de leis voltados especificamente para a concessão de isenção nos tributos de importação de acessórios, equipamentos e medicamentos. Esse estudo é descritivo e tem por base o referencial teórico e a análise qualitativa e quantitativa. A pesquisa qualitativa, segundo Minayo (2002, p. 22), "trabalha com o universo de significados, motivações, aspirações, crenças, valores e atitudes, o que corresponde a um espaço mais profundo das relações, dos processos e dos fenômenos que não podem ser reduzidos à operacionalização de variável". Segundo Minayo (2002, p. 43): "esse tipo de pesquisa (qualitativa) não pode basear-se no critério numérico, para poder garantir sua representatividade. A amostragem boa é aquela que possibilita abranger a totalidade do problema investigado em suas múltiplas dimensões." Sob as abordagens, Gil (2002) esclarece:

A pesquisa qualitativa responde a questões muito particulares. Ela se preocupa, nas ciências sociais, com um nível de realidade que não pode ser quantificado. Ou seja, ela trabalha com o universo de significados, motivos, aspirações, crenças, valores e atitudes, o que corresponde a um espaço mais profundo das relações, dos processos e dos fenômenos que não podem ser reduzidos à operacionalização de variáveis (GIL, 2002, p. 21-22). 
Já pesquisa quantitativa, de acordo com Minayo (2002), possibilita que sejam identificados os elementos que fazem parte do escopo do estudo, possibilitando que ocorra uma evolução dos elementos da estrutura do trabalho. Bardin (2011), salienta que a análise sob a perspectiva quantitativa considera como informação a ser privilegiada as características do conteúdo da investigação que se evidenciem com maior frequência. Já no que tange à análise qualitativa dos elementos constituintes do material pesquisado, o processo se dará por meio da observação em relação a presença ou ausência de determinada(s) característica(s) de conteúdo. Os métodos qualitativos e quantitativos se completam. Isso porque, mesmo sendo distintos no que diz respeito à forma e à ênfase, a metodologia qualitativa contribui com o entendimento dos diversos fenômenos (Bardin, 2011).

A pesquisa descritiva é própria para estudos cujo objetivo é conhecer as características de determinados grupos, e, assim, é preciso analisar a relação entre as variáveis bem como os impactos de implantação de um programa específico. Os dados oriundos de uma pesquisa descritiva possibilitam um melhor direcionamento a ser seguido. Vergara (2010), afirma que a pesquisa descritiva não têm o compromisso de explicar os fenômenos que descreve, embora sirva de base para tal explicação. Preliminarmente, a pesquisa teve como embasamento um levantamento bibliográfico, e, a partir dele, foram analisados artigos e livros que versam sobre 0 tema desse estudo. Para Vergara (2010): "Pesquisa bibliográfica é o estudo sistematizado desenvolvido com base em material publicado em livros, revistas, jornais, redes eletrônicas, ou seja, material acessível ao público em geral". De acordo com Gil (2002), a principal vantagem da pesquisa bibliográfica é a possibilidade de o pesquisador verificar uma série de fenômenos de forma mais ampla.

\section{RESULTADOS}

Devido à relevância do assunto, várias propostas de lei têm sido sugeridas por deputados, visando à isenção de tributos de importação de equipamentos e acessórios para portadores de necessidades especiais. Trata-se de pauta importante, mas, embora tenham projetos de lei, todos seguem sem uma resolução definitiva (Almeida, 2011). No Brasil, quem pode importar qualquer tipo de equipamento 
eletrônico tem o mesmo tributo de importação a ser pago que os que necessitam trazer do exterior. Como exemplo, pode-se mencionar o caso da aquisição de uma cadeira de rodas ou até uma bengala específica para cegos (Cantarelli, 2015). Os portadores de necessidades especiais costumam ter uma despesa de cerca de $60 \%$ de imposto na alfândega. Isso porque ao serem somados os impostos alfandegários aplicados, o valor dos produtos chega a duplicar e, em alguns casos, até a triplicar.

A grande maioria dos aparelhos tecnológicos para as pessoas cegas são importados, ou seja, cerca de $90 \%$ desses produtos são oriundos de outros países e isso dificulta o acesso de significativa parte da população que necessita desses produtos (Cantarelli, 2015). Equipamentos e acessórios destinados a portadores de necessidades especiais, como, por exemplo, produtos imprescindíveis para uma maior inclusão dessas pessoas são mais caros devido aos impostos que não são diferenciados dos outros produtos existentes no mercado, ou seja, elas não tem isenção de impostos na importação pagando o mesmo que um cidadão comum paga comprando no exterior e trazendo em sua bagagem[14]. As cadeiras de rodas motorizadas propiciam uma maior mobilidade e autonomia para pessoas portadoras de necessidades especiais, principalmente as que possuem uma mobilidade reduzida.

Atualmente, esses equipamentos importados sofrem taxação de até $180 \%$, tornando inviável a sua aquisição para a maioria das pessoas que necessitam deles para levar uma vida normal (Cantarelli, 2015). O Instituto Laramara[15] ainda é um dos poucos que consegue importar, de maneira legal, os equipamentos tecnológicos voltados para acessibilidade de pessoas com necessidades especiais. Entretanto, todos os impostos são pagos e apesar de toda a renda ser destinada a outros projetos de inclusão para os deficientes visuais, ainda são oferecidos cerca de 200 produtos a um custo muito alto. Vários Projetos de Lei tem sido impetrados com a intenção de conseguir que sejam obtidas isenções de tributos cobrados na importação de acessórios e equipamentos para Portadores de Necessidades Especiais. Para melhor entendimento, cada projeto será analisado individualmente.

a) Projeto de Lei 7.916/2010 
Esse Projeto de Lei trata da isenção do imposto de importação na aquisição de equipamentos por pessoas portadoras de necessidades especiais. Tal projeto foi apresentado pelo deputado Gonzaga Patriota (PSB-PE) em 17 de novembro de 2010. Ele levou dois anos para entrar em pauta na Câmara dos Deputados e está sem movimentação desde 5 de março de 2015 em Sessão Deliberativa Ordinária, sob a alegação de que o mesmo foi declarado prejudicado devido a aprovação da Subemenda Substitutiva Global apresentada ao Projeto de Lei n. 7.699/2006 principal[16].

b) PL 1.311/2015

Esse Projeto de Lei foi apresentado pelo deputado Pompeo de Mattos (PDT-RS), que: "Acrescenta incisos I e II, ao art. 3ํ, da Lei Federal № 10.754, de 31 de outubro 2003"[17]. Em 2019 o referido Projeto foi arquivado nos termos do Art. 105 do Regimento interno da Câmara dos Deputados. Em 4 de fevereiro de 2019, o Deputado Federal Pompeo de Mattos solicitou o desarquivamento da PL 1311/15, visto que ele já tinha sido arquivado em 31 de janeiro de 2019[18]. A Comissão de Finanças e Tributação da Câmara dos Deputados aprovou a concessão de isenção do Imposto de Importação (II) a aparelhos auditivos e cadeiras de rodas para portadores de necessidades especiais pelo prazo de cinco anos, a partir da entrada em vigor da lei. Tal texto substitui a PL 1311/15 do deputado Pompeo de Mattos (PDT-RS). Embora tais produtos já sejam isentos de Imposto sobre Produtos Industrializados (IPI), em conformidade com o Decreto ํㅜ 7.660/11, as cadeiras de rodas ainda são taxadas pelo Imposto sobre a Importação, sendo de $2 \%$ a alíquota para modelos a propulsão e de $12 \%$ para os outros. No entanto, os aparelhos que facilitam a audição de portadores de deficiência auditiva são totalmente isentos.

c) PL 4.645/2016

A proposta (PL 4645/16), cujo projeto é do deputado Flavinho (PSB-SP), busca isentar o pagamento de quatro tipos de tributos (Imposto sobre Produtos Industrializados (IPI), PIS/Pasep, Contribuição para o Financiamento da Seguridade Social (Cofins) e Imposto sobre Importação) de produtos assistivos fabricados para uso por pessoas 
com deficiência, tais como muletas, órteses e próteses e cadeiras de rodas. Anteriormente, essa isenção era dada na compra de produtos de fabricação nacional e importados que não possuíam um modelo similar nacional. No caso dos produtos importados que possuem um similar nacional, a alíquota dos tributos precisa ter um desconto do $50 \%$, no mínimo. Tal proposta tem como foco todos os produtos classificados como assistivos pela Associação Brasileira de Normas Técnicas (ABNT)[19].

d) PL 6.277/16

O Projeto de Lei 6277/16, do deputado Felipe Bornier (Pros-RJ), objetivou a concessão da isenção do Imposto sobre Produtos Industrializados (IPI) para órteses e outros produtos voltados para os portadores de necessidades especiais. Após inúmeras fases, em janeiro de 2019 o Projeto foi arquivado e, posteriormente, em fevereiro, foi desarquivado para prosseguimento de análise. É de suma importância que sejam aperfeiçoadas as normas que concedem isenções às pessoas com deficiências física, visual, auditiva, mental e autismo e às pessoas que convivem com doenças graves, a fim de efetivar a promoção da dignidade da pessoa humana, fundamento básico da República Federativa do Brasil. As isenções de impostos, seja no âmbito estadual, municipal ou federal, ainda são escassas e de pouco conhecimento da maior parte das pessoas, inclusive das que mais precisam. As políticas públicas do Poder Público ainda são insuficientes, sobretudo no que diz respeito à promoção e proteção das pessoas com deficiências. Diante disso, é necessário novos Projetos de Lei que enfatizam a necessidade de concessão de isenção de impostos tributários para aquisição de equipamentos que facilitam a acessibilidade dessas pessoas.

\section{DISCUSSÃO}

Nos últimos anos, tem crescido a preocupação por parte da sociedade no que diz respeito aos direitos das Pessoas com Necessidades Especiais. São lançadas, constantemente, campanhas que buscam uma maior conscientização por parte do Poder Público, buscando uma maior integração social por parte dessas pessoas. 
Mesmo com a diminuição da discriminação com o passar dos anos, ainda fica claro que a acessibilidade dessas pessoas possui limitações. Dessa forma, levando em consideração os ditames da Constituição Federal de 1988, a igualdade é um dos valores básicos e que precisa ser cumprido, embora ainda seja ignorado, mesmo que de forma menos agressiva do que antes. A Convenção dos Direitos da Pessoa com Deficiência tem se mostrado um importante instrumento para uma maior inclusão, propiciando a concretização de seus direitos fundamentais, principalmente aqueles ligados à igualdade (Araújo, 2001; Sassaki, 2008).

O Brasil, ao acatar os ditames jurídicos estabelecidos pela Convenção dos Direitos da Pessoa com Deficiência, demonstra um maior comprometimento com um assunto de tamanha relevância (Araújo, 2001; Sassaki, 2008). Tal realidade jurídica propicia que essas pessoas, quando se deparam com a omissão por parte do Estado, possam brigar pelos seus direitos diante do Poder Executivo por meio de denúncias no Poder Judiciário (Lopes, 2009; Silveira, 2010). No entanto, as ações realizadas pelas políticas públicas brasileiras demonstram que o poder público tem atendido de forma consistente tal dever, ou seja, conseguem atender os compromissos estabelecidos na Convenção (NISHIYAMA; TEIXEIRA; SILVA, 2016). No que diz respeito aos aspectos ligados à tecnologia assistiva, ainda se observa uma ineficácia das políticas públicas quanto à provisão de equipamentos e produtos que deem um suporte na minimização das barreiras que dificultam a vida profissional e social das pessoas com necessidades especiais.

Tais ações, para serem eficazes, precisam ser planejadas e implementadas para posterior monitoramento e avaliação (Pnitta III, 2017). Nesse sentido, as políticas públicas precisam atuar em todos os níveis institucionais por meio de programas permanentes e não somente em ocasiões especiais, devem estabelecer um nível bom de recursos nos orçamentos realizados anualmente, elaborar novas leis sobre o assunto, treinar os profissionais, cuidar da regulação dos vários interesses coletivos, articular as ações de maneira intersetorial e participar de forma mais ampla da sociedade civil (Nishiyama, 2016). Diante das limitações impostas aos Portadores de Necessidades Especiais, a tecnologia assistiva é imprescindível para a acessibilidade 
e, para tanto, muitas pessoas gostariam de importar acessórios e equipamentos, mas o entrave é o alto custo com o imposto de importação.

Muitos projetos foram impetrados buscando a concessão de isenção de impostos de importação para esse público alvo, entretanto, ainda não foram aprovados, em sua maioria, por questões orçamentárias. A importância dessa isenção é claramente demonstrada ao verificar os dados do IBGE (2010) que ilustram o número expressivo de Portadores de Necessidades Especiais no Brasil. Mais recentemente, buscando maximizar a discussão sobre o monitoramento de dados sobre pessoas com deficiência no Brasil, o Instituto Brasileiro de Geografia e Estatística (IBGE) realizou um novo lançamento no ano de 2018 sobre o Panorama Nacional e Internacional da Produção de Indicadores Sociais. Tal documento conseguiu apresentar dados com maior especificidade de diversos grupos, e, dentre eles, estão as pessoas portadoras de necessidades especiais.

Um dos objetivos desse documento é identificar eventuais lacunas existentes em amostragens anteriores (PNS, 2018). Ao serem confrontados os dados do Censo do IBGE (2010) com a pesquisa realizada em 2018, observou-se uma discrepância no percentual das pessoas com deficiência no Brasil. Isso porque, como já mencionado anteriormente, segundo os dados do IBGE de 2010 , o percentual era de $23,9 \%$, entretanto, nessa nova pesquisa, a proporção das pessoas com deficiência diminuiu muito, chegando a 6,7\%. Como explicar essa drástica redução? Não se pode negar que a isenção sobre o imposto de importação de cadeiras de rodas gera um alto impacto na arrecadação federal, mas é preciso que seja acordado pela concessão para os portadores de necessidades especiais. Para minimizar os impactos na arrecadação se faz necessária uma adequação orçamentária e financeira da proposta e tal benefício tem que ser previsto em lei, como forma de garantir-Ihe estabilidade[20].

Após analisar os dados ligados ao acesso das pessoas com necessidades especiais a produtos e serviços inovadores em tecnologia assistiva, observou-se que é possível e desejável maximizar o número de desfechos positivos no que tange à sua introdução no mercado, visto que se trata do objetivo principal de acessibilidade (Pnitta III, 2017). Recomenda-se uma maior maximização dos itens a serem utilizados por pessoas com 
necessidades especiais por parte das instituições que realizam projetos de (PD\&l) Pesquisa e desenvolvem produtos para Tecnologia Assistiva. Isso porque a demanda é grande, mas, no Brasil, ainda são poucos os produtos de acessibilidade que contam com a inovação e tecnologia. Dessa forma, será possível melhorar os resultados da inovação, visto que o objetivo final da tecnologia assistida é a melhora da funcionalidade e a maximização da vida profissional e social.

É preciso aprimorar esses equipamentos. (Pnitta III, 2017). Embora a inovação seja um processo que envolve incertezas e riscos, especialistas recomendam maior atenção ao item de previsibilidade de inserção no mercado do novo produto ou serviço de tecnologia assistiva nos processos seletivos das instituições desenvolvedoras de projetos ou das instituições de fomento. É necessária uma previsão das maiores possibilidades de sucesso final, isto é, de acesso por parte das pessoas com deficiência ao novo produto de tecnologia assistiva a ser criado (Pnitta III, 2017).

Quanto ao questionamento relacionado ao cumprimento por parte do Estado do seu dever de estabelecer os Direitos das Pessoas com Necessidades Especiais, verificase que essa questão é absorvida pelos órgãos gestores ligados aos direitos humanos que tem como papel primordial a articulação e a coordenação das políticas e a execução das mesmas são direcionadas aos responsáveis por cada área setorial (Nishiyama, 2016). Mesmo que o Estado demonstre ser solidário com as situações enfrentadas pelas pessoas com necessidades especiais, adotando forma jurídicas de proteção dos seus direitos, ainda são insuficientes e necessitam de ajustes urgentes nesse sentido (Nishiyama, 2016). Não é suficiente, apenas, leis securitárias e trabalhistas e programas que buscam a integração da pessoa portadora de necessidades especiais à sociedade. É necessário que todas as ações sejam implementadas a partir do Poder Público de maneira mais ativa (NISHIYAMA; TEIXEIRA; SILVA, 2016).

\section{CONSIDERAÇÕES FINAIS}

Diante do exposto, conclui-se que todos os objetivos (geral e específicos) foram alcançados. Isso porque foi verificado, por meio de levantamentos e estudos de leis e 
de projetos de leis, que os incentivos e subsídios a que os Portadores de Necessidades Especiais têm direito para importação de acessórios, equipamentos e medicamentos ainda não têm sido aplicados de maneira correta e ampla. Além disso, foram descritos os elementos conceituais e o panorama dos Portadores de Necessidades Especiais no Brasil e no Mundo; abordados os Direitos das Pessoas com Necessidades Especiais, enfatizando o seu papel no Plano Internacional e os Documentos Internacionais de Proteção a essas pessoas e foi abordada a questão da acessibilidade como Direito Fundamental das Pessoas com Necessidades Especiais.

Descreveu-se as várias dimensões existentes de acessibilidade e as questões ligadas a tributação e os Portadores de Necessidades Especiais, destacando a sua capacidade contributiva e as isenções de tributos a que têm direito, dentre os quais, os ligados à importação de acessórios, equipamentos e medicamentos e analisou-se analisar os projetos de Lei ligados às isenções de importação bem como as Leis já aprovadas e, por fim, verificou-se os desafios ainda a serem enfrentados nesse sentido. A busca pela concessão de isenção de impostos tributários para aquisição de equipamentos necessários para a inclusão dos Portadores de Necessidades Especiais reflete uma preocupação pela maior qualidade de vida dessas pessoas, entretanto, são muito lentas no sentido de trazer resultados efetivos mais rapidamente.

É necessário uma maior conscientização acerca da necessidade de aumentar esse direito a essas pessoas. Os resultados esperados foram concretizados, visto que a pesquisa trouxe dados suficientes que comprovam a importância da isenção de impostos para importação de acessórios, equipamentos e medicamentos para Portadores de Necessidades Especiais (PNE). Essa comprovação foi embasada nos dados apresentados pelo IBGE (2010) e pela Pesquisa Nacional de Saúde (2018), que demonstram, claramente, que o número de Portadores de Necessidades Especiais é grande e merece atenção especial. Embora os Portadores de Necessidades Especiais ainda não sejam isentos dos impostos de importação de acessórios, equipamentos e medicamentos, foram apresentados os demais tributos 
os quais eles têm isenção e que, por vezes, ainda não tem conhecimento sobre esses direitos.

Enquanto não se converte em lei os projetos de isenção desse imposto de importação, a indústria brasileira tem se esforçado para fornecer acessórios que tenham uma qualidade superior. Após o exame dos resultados do acesso das pessoas com deficiência a produtos e serviços inovadores em tecnologia assistiva, conclui-se que é possível e desejável a maximização do número de desfechos positivos quanto à sua introdução no mercado, propiciando, dessa forma, o aumento da acessibilidade as Pessoas com Necessidades Especiais. Fica clara a falta de vontade política no sentido de transformar em lei todos os projetos aqui mencionados, prejudicando, dessa forma, o interesse dos portadores de necessidades especiais, infringindo, então, o direito desses de terem uma melhor acessibilidade.

Para que isso ocorra, recomenda-se que sejam adotadas algumas ações, tais como o aumento da Pesquisa e Desenvolvimento e Inovação em Tecnologia Assistiva assim como as instituições de fomento da inovação precisam dar uma importância maior aos itens cuja demanda é maior e que não estão sendo bem assistidos. Devido ao crescimento da inovação em tecnologia assistiva e a insuficiência de cobertura do mercado e da disponibilização de produtos assistivos, recomenda-se o aumento progressivo da inovação em tecnologia assistiva na agenda das políticas públicas. Torna-se fundamental compreender que os produtos e serviços de tecnologia assistiva serão cada vez mais relevantes, pois se trata de artigos de primeira necessidade para a população com deficiência, idosa e com mobilidade reduzida. Sem eles, estas pessoas não podem desenvolver-se com autonomia, manter o controle de suas vidas ou aumentar sua participação social.

Essa provisão de produtos de apoio se insere, enquanto direitos das pessoas com deficiência, nas obrigações assumidas pelos poderes públicos. Deve ser acrescentado que uma grande parte dessas pessoas que precisam de produtos assistivos se encontra socialmente excluída dos fluxos da inovação global em que constantemente são criados produtos e tecnologias. Enquanto destinatárias e usuárias dessas inovações, elas poderiam beneficiar-se da aplicação dos princípios 
do desenho universal. Recomenda-se, ainda, novas pesquisas buscando, sobretudo, acompanhar o progresso desses projetos de Lei e as inovações da tecnologia assistiva. Pensar em tais questões justifica a relevância desse estudo para a academia, e, principalmente, para as pessoas com deficiência.

\section{REFERÊNCIAS}

Abreu. C. B. Curatela e interdição civil. Rio de Janeiro: Lumen Júris, 2009.

Almeida, D. V. A tributação e os portadores de necessidades especiais: The taxation and the people with special needs. Brasília: Conteúdo Jurídico, 2011.

Araújo, L. A. D. A proteção constitucional das pessoas portadoras de deficiência. 3a. ed. Brasília: CORDE, 2001.

Barcellos, A. P.; Campante, R. R. A acessibilidade como instrumento de promoção de direitos fundamentais. In: Ferraz, C. V.; Leite, G. S.; Leite, G. S.; Leite, G. S. (Coord.). Manual dos direitos da pessoa com deficiência. São Paulo: Saraiva, 2012.

Bardin L. (2011). Análise de conteúdo. SP: Edições 70.

Bolonhini Junior, R. Portadores de Necessidades Especiais: as principais prerrogativas e a legislação brasileira. - São Paulo: Arx, 2004.

Brasil. Constituição Federal. Constituição da República Federativa do Brasil. Brasília: Senado, 1988.

Brasil. Congresso Nacional. Estatuto da Pessoa com Deficiência. Lei no 13.146, de 06 de julho de 2015. Vade Mecum. 23ā. ed. São Paulo: Saraiva, 2017.

Cantarelli, D. F. Isenção de impostos para pessoas com deficiência e com doenças graves. Brasília: Conteúdo Jurídico, 2015.

Fávero, E. A. Direito das pessoas com deficiência: garantia de igualdade na diversidade. Rio de Janeiro: WVA, 2004, p. 22. 
Ferreira Filho, M. G. Curso de direito constitucional. 36ª ed. Rev. e atual. São Paulo: Saraiva, 2010.

Gil, A. C. Como elaborar projeto de pesquisa. São Paulo: Atlas, 2002.

Instituto Brasileiro de Geografia e Estatística. 2018. Panorama Nacional e Internacional da Produção de Indicadores Sociais. Grupos Populacionais Específicos e uso do tempo. Disponível em: http://biblioteca.ibge.gov.br/index.php/bibliotecacatalogo ?view=detalhes\&id=2101562. Acesso em: 01 mar. 2020.

Lopes, L.V.C.F. Convenção sobre os direitos das pessoas com deficiência da ONU e seu protocolo facultativo e a acessibilidade. 2009. 228 f. Dissertação (Mestrado em Direito) - Pontifícia Universidade Católica, São Paulo, 2009.

Lorentz, L. N. A norma da igualdade e o trabalho das pessoas portadoras de deficiência. São Paulo: LTr, 2006, p. 86.

Maio, M. C. O Projeto UNESCO e a Agenda das Ciências Sociais no Brasil dos anos 40 e 50. Revista Brasileira de Ciências Sociais, v. 14, n. 41, 1999.

Minayo, M. C. S. Pesquisa social: teoria, método e criatividade (Org.). 9ª ed. Petrópolis: Vozes, 2002.

Nishiyama, A. M. Proteção jurídica das pessoas com deficiência nas relações de consumo. Curitiba: Juruá, 2016.

Nishiyama, A. M.; Teixeira, C. N.; Silva, J. D. A proteção internacional dos hipervulneráveis: idosos, crianças e adolescentes e pessoas com deficiência. A necessidade de diálogos entre as pessoas internacionais. Revista Jurídica do Curso de Direito da Faculdade Cescage, v. 1, n. 5, p. 310-332, 2016.

Ohlweiler, L. P. Um introdução à Teoria Geral do Direito. Porto Alegre: Editora Verbo Jurídico, 2014. 
Oliveira, R A. O novo sistema de (in)capacidades e a atuação do MP na curatela. São Paulo: Atlas, 2016.

Requião, M. Autonomias e suas limitações. Revista de Direito Privado, ano 15, v. 60, 2016.

Sabbag, E. M. Direito Tributário. 8ª . ed. São Paulo: Premier Máxima, 2006.

Sassaki, R. K. Educação. In: RESENDE, A. P. C. de; VITAL, F. M. de. P (Coord.). Convenção sobre os direitos das pessoas com deficiência comentada. Brasília: Secretaria Especial dos Direitos Humanos. Coordenadoria Nacional para Integração da Pessoa Portadora de Deficiência - CORDE, 2008, pp.84-85.

Schreiber, A. Manual de Direito Civil Contemporâneo. São Paulo: Saraiva Educação, 2018.

Silveira, N. Celebrando a diversidade: o direito à inclusão. São Paulo: Planeta Educação, 2010.

Torres, R. L. Curso de direito financeiro e tributário. 17a․ ed. Rio de Janeiro: Renovar, 2010.

Vergara, S. C. Projetos e Relatórios em Pesquisa em Administração. São Paulo: Atlas, 2010.

Vorcaro, M. E. G. C. P.; Gonçalves, B. J. D. Análise objetiva das principais alterações advindas do Estatuto da Pessoa com Deficiência (lei 13.146/15). Rio de Janeiro: Lumen Juris, 2016.

\section{APÊNDICE - REFERÊNCIAS DE NOTA DE RODAPÉ}

2. Art. 4º, II, segunda parte, CC/02 (Redação antiga).

3. Art. 4ํㅡ, III, CC/02 (Redação antiga). 
4. Convênio ICMS - 03/07.

5. Redação dada pela Lei no 10.182, de 12.2.2001.

6. Redação dada pela Lei no 10.690, de 16.6.2003.

7. Idem.

8. Idem.

9. Redação dada pela Lei no 10.690, de 16.6.2003.

10. Idem.

11. Idem.

12. Idem.

13. Redação dada pela Lei no 10.754 , de 31.10.2003.

14.

Disponível

em:

http//www.mosaico.com.br/ canal=3\&pg=show_noticias_informativa\&in=359\&path $=$ Noticias\&idp $=$. Acesso em: 10 jan 2019.

15. Disponível em: www.laramara.org.br. Acesso em: 23 fev. 2019.

16

Disponível

em:

https://www.camara.leg.br/proposicoesWeb/fichadetramitacao?idProposicao=486930 . Acesso em: 15 jan. 2019.

17. Lei 10.754 de 2003 - Altera a Lei no 8.989, de 24 de fevereiro de 1995 que "dispõe sobre a isenção do Imposto Sobre Produtos Industrializados - IPI, na aquisição de automóveis para utilização no transporte autônomo de passageiros, bem como por pessoas portadoras de deficiência física e aos destinados ao transporte escolar, e dá outras providências. 
18.

Disponível:

https://www.camara.leg.br/proposicoesWeb/fichadetramitacao?idProposicao=121596 9. Acesso em: 12 fev. 2019.

19. Disponível em: http://www.fernandazago.com.br/2016/08/isencao-de-impostospara-cadeira-de.html?m=1. Acesso em: 20 jan. 2019.

20.

Disponível

em:

http://www2.camara.leg.br/camaranoticias/noticias/SAUDE/503633-COMISSAOISENTA-CADEIRAS-DE-RODAS-E-APARELHOS-AUDITIVOS-DO-IMPOSTO-DEIMPORTACAO.html. Acesso em: 18 jan. 2019.

Enviado: Dezembro, 2019.

Aprovado: Março, 2020. 